\title{
Forest-bathing and physical activity as weapons against COVID-19: a review
}

\author{
Valentina Roviello ${ }^{1} \cdot$ Melinda Gilhen-Baker ${ }^{2} \cdot$ Caterina Vicidomini $^{3} \cdot$ Giovanni N. Roviello $^{3}$ (C)
}

Received: 24 August 2021 / Accepted: 4 September 2021 / Published online: 21 September 2021

() The Author(s), under exclusive licence to Springer Nature Switzerland AG 2021

\begin{abstract}
Strengthening the immune system in order to better withstand the threat of COVID-19 is an important way to ensure the protection of our health against the current pandemic associated with SARS-CoV-2. There are many ways to achieve this, but with current circumstances, certain modalities stand out as being the most valid and are certainly worth greater consideration. Here we review the effects that particular immuno-strengthening activities can have on limiting the severity of COVID-19 disease as well as preventing virus infection. Physical activity, in particular, should not be discounted as an important method of prevention of viral diseases as it triggers many biological processes within the human body which in turn lead to heightened natural defences against viral infections. When exercise is performed in forested areas, these protective health benefits may be increased since many plant species emit biogenic volatile compounds (VOCs) which, when inhaled, have many protective properties. These VOCs have been shown in particular to have immunostimulatory effects on the human body and, thus, they could be of use in the prevention and/or treatment of COVID-19. Being amongst trees may also help to alleviate stress and anxiety, lowering cortisol levels and consequently helping the proper functioning of the immune system. In the following work, we have performed an analysis of the available scientific literature which looks at the effects of physical exercise as well as 'forest-bathing' on the immune system's ability to fight disease, especially of course as it relates to COVID-19. Our review aims at shedding light on the benefits of exercising outdoors in green areas and suggests reforestation as a protective measure against future outbreaks.
\end{abstract}

Keywords COVID-19 · Body immunity $\cdot$ Physical activity $\cdot$ Forest-bathing $\cdot$ Volatile organic compounds

\section{Introduction}

With continued deforestation and an increase in air pollution resulting in poorer air quality, it is not surprising that acute viral respiratory infections should be among the main infectious diseases affecting humanity today. At the beginning of

Valentina Roviello and Melinda Gilhen-Baker equally contributed to this work.

Giovanni N. Roviello

giroviel@unina.it

1 Department of Chemical, Materials and Industrial Production Engineering (DICMaPI), University of Naples Federico II, Piazzale V. Tecchio 80, 80125 Naples, Italy

2 Faculty of Physical Medicine and Rehabilitation, Georgian State Teaching University of Physical Education and Sport, 49, Chavchavadze avenue, 0162 Tbilisi, Georgia

3 Istituto di Biostrutture e Bioimmagini, IBB - CNR Mezzocannone Site and Headquarters, 80134 Naples, Italy
2020, the world witnessed the spread of one such disease caused by severe acute respiratory syndrome coronavirus 2 (SARS-CoV-2), which led to the coronavirus disease 2019 (COVID-19) (Chathappady House et al. 2021). This new virus disease resembles both the severe acute respiratory syndrome (SARS) and the Middle East respiratory syndrome (MERS) through its similar immunopathology (Chathappady House et al. 2021). Originating in China, COVID-19 rapidly became of much greater concern as it succeeded in spreading around the globe, resulting in the current pandemic. To date, there have been more than 4,200,000 deaths associated with the disease globally (https://www.world ometers.info/coronavirus/ accessed on 1st August 2021). The pandemic has also been the cause of great instability in the world's economies and has forced many countries to face difficult sanitary conditions with overcrowded hospitals and morgues. While the global mass immunization efforts have begun and many are hopeful to have found in it a mid-term solution (Costanzo et al. 2021), new virus variants are still 
causing concern and there is uncertainty as to whether or not the vaccine will offer adequate protection (Zhou et al. 2021). Until mass vaccination has proven successful, there are many research groups continuing their exploration of other immediate solutions. One such possibility currently being tested is the trial of therapies among those already known to be effective in the treatment of other viral diseases, as well as COVID-19-related disorders (Costanzo et al. 2020). This approach, called 'drug repurposing' can indeed be a quick way to find treatment options for the current pandemic. Of course looking into ways of preventing further outbreaks and strengthening human defenses against such diseases is also of great importance.

So far, it has been made clear that to effectively combat and prevent the incidence of COVID-19, maintaining a healthy body, more particularly, a strong immune system, is crucial. Of course, the fact that the body's immune system plays a central role in combatting viral diseases, including COVID-19, comes as no surprise (Dai et al. 2021). However, the lockdown measures put in place by government leaders around the world as a reaction to the rapid virus spread has led to poor lifestyle habits (Ammar et al. 2020). With mental health issues on the rise, many have turned to unhealthy eating habits, increases in alcohol intake as well as limiting or altogether abandoning their physical activities. Remaining indoors or being forced to stay within the confines of their cities also limits people's exposure to green spaces and the protective medicinal aerosols emitted by the surrounding trees. This is particularly true for the older demographic which are at higher risk for COVID-19 and so more inclined to stay in isolation. They would benefit from an increase in exercise to both strengthen their immune and cardiovascular systems which in turn would help to combat and protect against hypertension, type- 2 diabetes mellitus as well as several other chronic disorders common in geriatric populations (Lakicevic et al. 2020; Sepúlveda-Loyola et al. 2020; Malaguarnera et al. 2008). The COVID-19 outbreak has then resulted in large portions of the population having a less healthy and active lifestyle, as well as a rise in stress, anxiety and other mental health issues, which conversely leaves them at higher risk of infection.

Herein, our aim is to gather and report on the information available with regards to how physical activity can act as a preventative measure against the onslaught of COVID-19. Expanding on this, we look into the well documented protective role of biogenic volatile organic compounds (VOCs) emitted by certain plants which have both immunomodulatory and antiviral properties. Ultimately, our intention is to promote a healthy level of exercise, done outside in green spaces such as parks or forested areas where an abundance of trees is present. We hope that this will also encourage a stronger interest in investing in reforestation as a means to protect the health of people everywhere. To complete this work, our search strategy mainly consisted of considering articles published between January 2020 and June 2021 with themes COVID-19 and physical activity, as well as COVID-19 and forest-bathing. The search was carried out between March 19th, 2021 and July 30th, 2021. The databases searched were MEDLINE, PubMed, Google Scholar, and Google. Conversations with Botanist and Biochemist, Diana Beresford Kroeger were also included as well as other recent studies on the benefits of forest bathing. Only studies reported in English were included.

\section{Physical activity as a viable means of increasing immune response to COVID-19}

The modulatory effects of physical activity on the immune system have been verified. To be precise, exercise increases lymphocyte circulation and activates the release of several cytokines (Shek and Shephard 1998). People who practice sport on a regular basis experience less dramatic symptoms and a lower mortality rate due to viral infections (Chastin et al. 2021). Physical exercise also leads to increased levels of type I interferons (IFN-I) which in turn initiate the action of lymphocytes and macrophages (da Silveira et al. 2020a,b). This is particularly interesting for COVID-19 patients who have been found to have suppressed levels of this type of interferons. Physical activity also boosts the immune system and stimulates the release of cytokines which, with their anti-inflammatory properties, aid in counteracting lymphopenia and the increase in pro-inflammatory cytokines present in COVID-19 patients (da Silveira et al. 2020a,b).

Recently, it has been reported that there is a direct link between the COVID-19 virus and certain chronic disorders such as hypertension and type 2 diabetes mellitus (Alyammahi et al. 2021). With lockdown measures being widely implemented, many people, including hypertensive and diabetic patients, have been limiting their physical activities. This has led to a global decrease in the cardiovascular and immune system strengthening benefits related to participation in sport. Physical activity may also affect one's susceptibility to viral infections in particular since it activates the autonomous nervous system and the related immunoregulatory hormones which form the basis of the immune response (Jesus et al. 2021). Moreover, exercise triggers other beneficial changes in the human body such as the modification of the phenotype and levels of released cytokines, not to mention the distribution of monocytes and lymphocytes (Jesus et al. 2021). However, the level of physical activity can have a big impact on the protective effects provided. More intensive physical exercise, such as the vigorous and prolonged training programs used by athletes, has conversely been associated with immune dysfunction. Indeed, such acute exercise regimes can cause suppressed 
salivary immunoglobulin A release, lower activity of natural killer cells and reduced function of B- and T-cells as well as an increased risk of illness which includes infections of the upper respiratory tract (Jesus et al. 2021). On the other hand, moderate yet sustained levels of physical activity induce specific immunomodulatory changes which are beneficial in the prevention of cancer as well as cardiovascular disorders. Looking at this from a quantitative perspective, a study was conducted on individuals performing low-volume exercise ( $15 \mathrm{~min} /$ day for 6 days a week) where the group in question showed a decrease in an all-cause mortality at a rate of $14 \%$ as well as a $20 \%$ reduction in deaths associated with cardiovascular disease when compared to the more sedentary group (Jesus et al. 2021). Indeed, thanks to the immunomodulatory benefits of physical activity, an increase in mitochondrial fatty acid oxidation led to an improved anti-inflammatory response in individuals with previously inactive lifestyles who began a program of low-intensity workouts. Such dysfunctions of a host's defenses against oxidation can be at least partially responsible for the severe inflammation induced by viral respiratory infections and that including those associated with coronaviruses.

It is then of interest that in animal models infected with the influenza virus, chronic and moderate physical activity has been found to reduce the viral load and the related severity of the disease (Montgomery et al. 2008). This also led to a decrease in overall mortality and incidence rate while increasing the anti-inflammatory effects when compared to those subjected to a regime of acute exercise. Regular physical activity does in fact stimulate a particular antioxidant response which occurs by way of the Nrf2 (nuclear factor erythroid 2-related factor 2) which is a transcription factor involved in both the lowering of cardiovascular risk and antimicrobial defense. Bringing this forward, the fact that a high percentage of COVID-19 patients requiring intensive care are overweight or suffering from obesity suggests a correlation between the lack of an adequate exercise routine and the severity of the disease in question (Salvadori et al. 2021). Of course, preexisting comorbidities that come with an excess in weight such as cardiovascular disease, hypertension and diabetes also affect the body ability to fight the infection. However, even after adjusting available data to take into account factors such as the presence of these particular ailments as well as age, gender and other lifestyle related risks, findings still suggest that people suffering from obesity are at a higher risk of a more severe case of COVID-19 (Dalamaga et al. 2021). It is then clear that chronic moderate physical activity should be considered beneficial in the prevention of viral respiratory infections, including that due to SARS-CoV-2 and its resulting inflammation (Jesus et al. 2021; Salgado-Aranda et al. 2021). This brings us to the types of exercise which recent literature suggests are of optimal use in the prevention of COVID-19 and other coronavirus-related diseases. For individuals who are in good health to begin with, these include respiratory muscle training as well as aerobic and resistance training. Such gentle strengthening exercises as tai chi (Xu et al. 2021) and yoga have also been suggested as stress reducing and immuno boosting exercises for the prevention of COVID-19 (Dai et al. 2021). Patients already suffering from upper and lower respiratory tract illnesses should limit their physical activity to respiratory muscle training. With the varied health of the population and diverse possible response to physical training, a personalized program is recommended to ensure a positive outcome against SARS-CoV-2 in particular (Codella et al. 2021; Dominski and Brandt, 2020).

\section{Nutrition and diet as a supplementary aid to the management of COVID-19}

In addition to physical exercise, nutrition plays a fundamental role in the prevention and management of COVID19. For example, omega- 3 fatty acids, vitamins $C$ and D as well as regular consumption of a variety of fruits and vegetables is recommended to support the body's immune system regardless of one's state of health (Iddir et al. 2020). Vitamin A, E, iron, zinc and both selenium and copper are of particular use in strengthening the immune system against infectious disease (Cervantes-Pérez et al. 2020). This, however, becomes especially important for patients affected by COVID-19 (Khoramipour et al. 2021). Although evaluating the adoption of any particular dietary supplementation to prevent or treat COVID-19 is difficult, a balanced diet which includes diverse micronutrients and sufficient amounts of macronutrients is considered one of the best practices to ensure the proper functioning of the immune system. In contrast, obesity and high-calorie diets with low nutritional value are major risk factors for severe and fatal cases of COVID-19 (Dalamaga et al. 2021). This suggests that body weight control is one of the most important preventive measures that should be undertaken in the prevention of coronavirus diseases. In fact, it has been shown that during the current pandemic, there has been a rise in consumption of highly processed, sodium laced foods which can lead to varied ailments such as hypertension and cardiovascular disease (Zhang et al. 2021). As shown, these diseases have been associated with more severe cases of COVID-19. Of course, limiting other lifestyle-related factors such as alcohol intake and smoking will also help insure that the immune system is functioning at its highest capacity (Lange and Nakamura, 2020). 


\section{Halting future zoonotic outbreaks; Forests as essential barriers to zoonoses}

Aside from adopting a healthy lifestyle including moderate but chronic physical exercise and a healthy nutritional program, there is another factor which has the potential to greatly aid in our fight against respiratory diseases which, sadly, is often overlooked. Spending time out of doors, under the canopy of trees, is an important and undervalued means to reinforce our body's ability to keep infections at bay. Forests are enormously important for the wellbeing of all life on earth and this for a number of reasons. They are the refuge of the most vulnerable human populations on the planet which use the forest as their pharmacies, their grocery stores, and indeed their main economic tool, and this especially during the current pandemic (Sen 2020). Moreover, they form precious buffer zones that protect us from contact with zoonoses; a concept which should be considered with greater urgency by both the global scientific community and local governments. More than half of all infectious diseases plaguing mankind as well as $75 \%$ of those found to be recently emerging derive from the transfer of pathogens, and especially viruses, originating from the animal kingdom (Sen 2020). These zoonoses become particularly relevant when natural habitats, such as forests and grasslands, are cleared to make way for the growth of our cities, for logging, as well as for agricultural expansion. This change of the natural landscape creates new ecotones which contribute to the emergence of zoonotic diseases (Despommiers et al. 2006). The loss of these natural landscapes reduces the separation between people and wild animals as well as from the pathogens that they may harbour. In areas of deforestation, the frequency of incidents involving contact between humans and animals can sometimes increase dramatically as many species are forced to roam further in search of food and shelter. In other words, when forests are reduced or disappear, the possibility for transmission of infectious diseases increases significantly (Sen 2020). Therefore, the degradation of forests, aggressive logging, and the illegal wildlife trade (such as those fueling illegal meat markets) all contribute to the emergence of zoonotic diseases and, potentially, to future pandemics. It is thus a strong possibility that if humanity continues to clear forests around the globe, we will continue to witness epidemic disease outbreaks. If, however, a global plan for forest conservation and restoration is seriously undertaken, it could play a deciding role in the reduction of interactions between humans and wild animals resulting in a decrease in the possibility for future zoonotic pandemic outbreaks.

\section{The medicines we breathe; forests as a cornucopia of pharmaceutical potential}

Forests offer much more than a barrier to zoonotic infections. Just as vital to us, particularly in our current situation, is the fact that they are a precious source of biogenic volatile organic compounds (VOCs) including phytoncides which have many positive biological effects on human health (Wang 2019). The practice of spending time amongst the trees is known in Japan as Shinrin-yoku or 'forest-bathing' and has been shown to be of therapeutic benefit with regards to improving mental and immune system health. In fact, the many documented physiological benefits of forest bathing include among others, a decrease in both pulse rate and cortisol levels which can affect the proper functioning of the immune system (Timko et al. 2020; Ochiai 2019) and which have brought interest for further study (Jones et al. 2021). In many other parts of the world, the benefits of walking in a wooded area is known but a medical approach that hands out such 'green prescriptions' is not common practice. Forest bathing has been lauded as a preventative measure which improves one's resistance to disease and is a well documented accessible method for both managing stress and promoting health (Yu and Lee, 2019; Wen et al. 2019; Seifert et al. 2020; Yau and Loke, 2020; Clarke et al. 2021; Peterfalvi et al. 2021). In particular, it has shown promise in the prevention of heart disease, diabetes, cancer and of specific interest here, respiratory diseases (Li 2019). Certain volatile terpene compounds emitted by trees, such as a-pinene, $\beta$-pinene, D-limonene, camphor and $\alpha$-terpineol to name a few, have also been found to be effective in the treatment of respiratory inflammation diseases and administering these compounds through forest bathing may be safer when compared to ingestion or topical application (Kim et al. 2020). As part of a therapeutic "bioplan", Diana Beresford Krueger has suggested that certain trees whose aerosol chemistry would accelerate the healing of the patients therein, should be planted around hospitals and these could be tailored to the specific illnesses the institution specializes in (Beresford-Kroeger 2019). Indeed, due to the vast proven therapeutic potential of forest bathing, it has been suggested that more studies should be done in order to determine which particular species of trees and exercise regimes are best to tackle each individual health condition (Doimo et al. 2020). Due to its particular aerosol composition and its strengthening effects on the respiratory system, the white pine or Pinus strobus is a North American example of a tree that could be beneficial in the prevention and treatment of COVID-19 [D BeresfordKroeger 2021, personal communication, May]. The balsam poplar or Populus balsamifera found especially in 
the Boreal Forests of North America, is also responsible for the release of an incredible amount of oleoresins and beneficial vapors which spread around, protecting the respiratory health of not just humans, but all mammals alike (Beresford-Kroeger 2013). These particular trees provide a whole host of medicinal compounds not only by way of aerosols, but also within its resins and propolis which contain linolenic and linoleic acid, bisabolol and arachidonic acid amongst other complex biochemicals for which we are only just beginning to understand the medical importance (Beresford-Kroeger 2013). These trees also produce particular groups of primary aerosols, which are released into the atmosphere. Their 6 forms, $\mathrm{E}_{1}, \mathrm{E}_{2}, \mathrm{E}_{3}, \mathrm{~F}_{1 \alpha}, \mathrm{F}_{2 \alpha}$, and $\mathrm{F}_{3 \alpha}$, have many crucial health benefits when inhaled including platelet aggregation and peripheral vasodilation (Beresford-Kroeger 2018). These findings all demonstrate the important medicinal potential of trees and support the idea that increasing accessibility to green spaces and ensuring the protection of our remaining forests may help slow the progression of this pandemic and prevent future outbreaks.

\section{Volatile organic compounds in two representative north-American trees: white pine and balsam poplar}

In this section, we aim at furnishing more details on two representative trees originating from North America mentioned in the previous section. Of these, the balsam poplar (Populus balsamifera) is a hardy, fast-growing deciduous tree (Fig. 1, left) which is known for the intense fragrance emanating from its resinous buds which have long been an important source of medicine for the indigenous Cree Nations of Eastern James Bay in Canada. It is used specifically as a remedy against obesity and diabetes; therapeutic properties which have also been demonstrated through scientific studies (Ouellet et al. 2016). Among the biogenic VOCs emitted by the balsam poplar, there are isoprene and terpenes like
Fig. 1 Balsam poplar leaves (upper left) and white pine branch tip with pine needles (upper right). A specimen of balsam poplar (lower left) and white pine (lower right). Photos taken by Melinda Gilhen-Baker in Cantley, Canada (white pine tree, $22^{\text {d }}$ July 2021. Balsam poplar full plant and leaves, $25^{\text {th }}$ July 2021) and Wakefield, Canada (white pine needles,

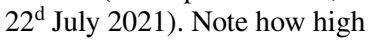
the white pine grows, emerging from the forest canopy. Besides its impressive stature, this coniferous species is evergreen, while balsam poplar is deciduous

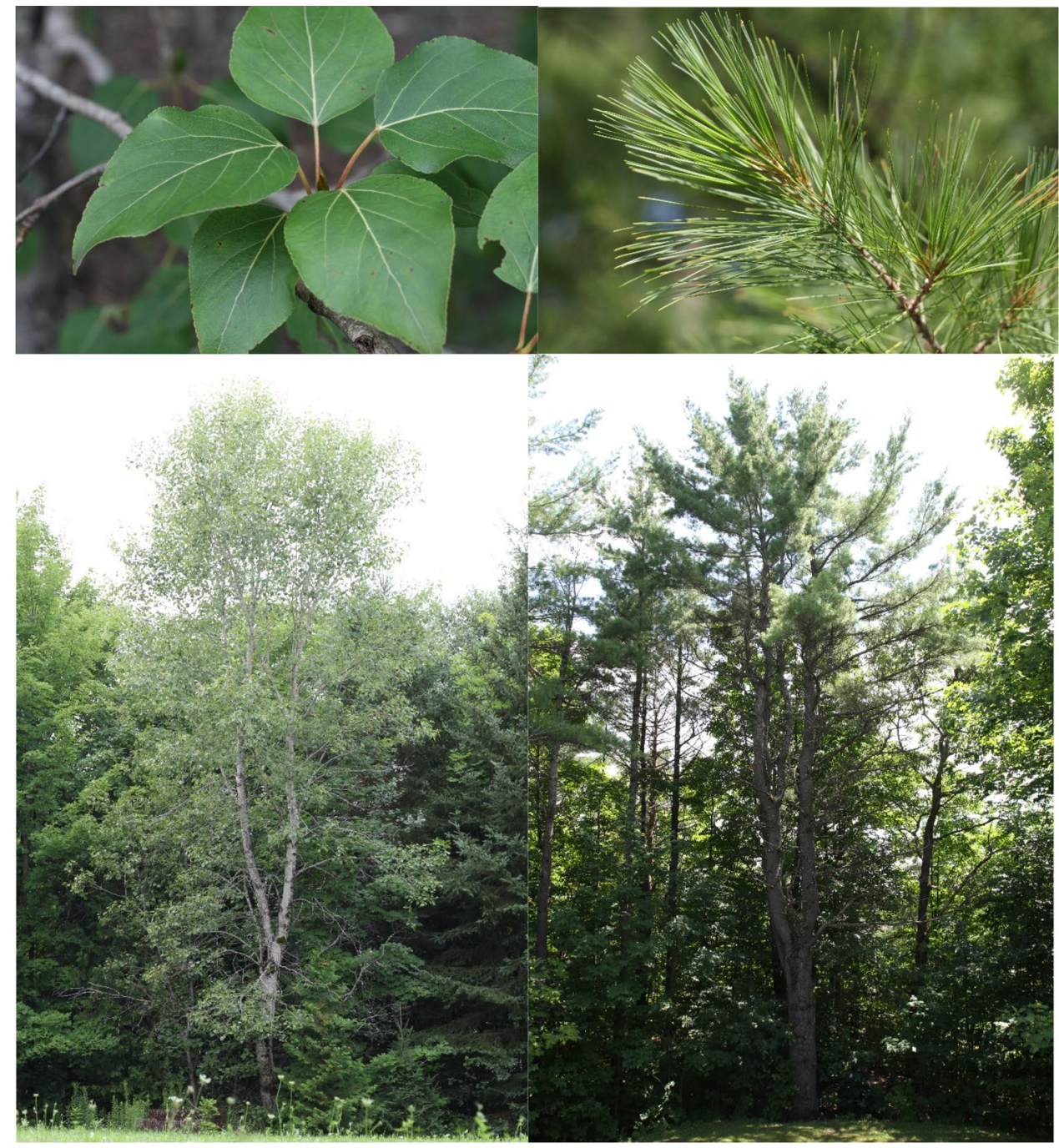


Fig. 2 Biogenic VOCs (volatile organic compounds) emitted by the balsam poplar. Note how all molecules (but isoprene) represented in this figure are classified as terpenes

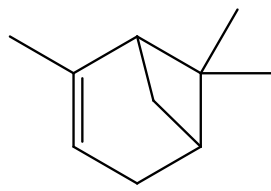

2,6,6-trimethylbicyclo[3.1.1]hept-2-ene $\alpha$-pinene

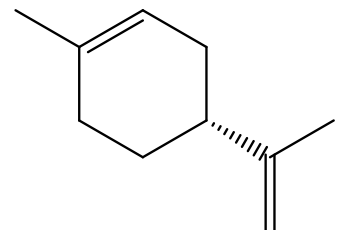

(4R)-1-methyl-4-prop-1-en-2-ylcyclohexene D-limonene

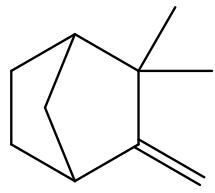

2,2-dimethyl-3methylidenebicyclo[2.2.1]heptane camphene

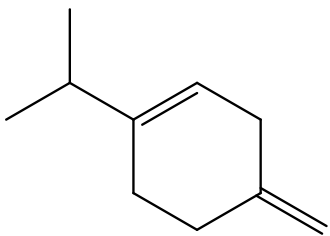

4-methylidene-1-propan-2-ylcyclohexene $\beta$-terpinene

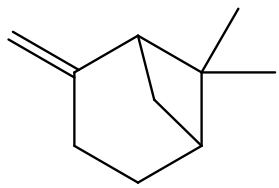

6,6-dimethyl-2-methylidenebicyclo[3.1.1] heptan $^{\mathrm{e}}$ $\beta$-pinene

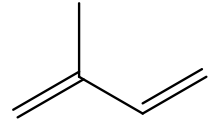

2-methylbuta-1,3-diene isoprene

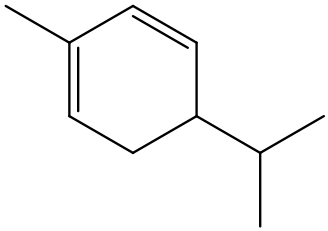

2-methyl-5-propan-2-ylcyclohexa-1,3-diene $\alpha$-phellandrene

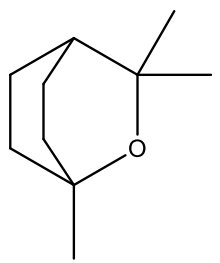

1,3,3-trimethyl-2-oxabicyclo[2.2.2]octane 1,8-cineol $\alpha$-pinene, $\beta$-pinene, $\alpha$-phellandrene, $\beta$-terpinene, 1,8 -cineol, camphene and D-limonene (Fig. 2) (Isidorov et al. 1985).

The white pine (Fig. 1, right) is a large evergreen conifer native to North America whose distribution ranges from Canada to the USA. Being the tallest tree in the forest, it is traditionally considered by indigenous communities as a plant of high cultural and spiritual importance, but also as a source of natural remedies for high blood pressure, heart diseases, tooth problems, swellings, muscle pain, and wounds (Uprety et al. 2013). Having been overharvested over the last centuries in North America, white pine abundance has severely decreased and in several regions it is currently considered as rare (Thompson et al. 2006). Owing to biogenic VOCs emitted by white pine (Fig. 3), the dominant terpenes are $\alpha$-pinene and $\beta$-pinene, while the most abundant sesquiterpenoid is germacrene-D-4-ol (Toma and Bertman, 2009). Nonetheless, significant amounts of limonene (Toma and Bertman, 2011) and germacrene D were also identified among the other VOCs emitted from this coniferous tree.

Interestingly, some VOCs emitted by balsam poplars and white pines were shown to be beneficial in the case of respiratory diseases. For example, as revealed in a placebo-controlled, double-blind trial 1,8-cineol (Fig. 2) shows clinical efficacy in inflammatory airway diseases, such as asthma and obstructive pulmonary disease (Worth and Dethlefsen, 2012; Juergens 2014). Moreover, $\alpha$-pinene (Figs. 2 and 3) was found effective against allergic rhinitis (Nam et al. 2014). 
Fig. 3 Biogenic VOCs (volatile organic compounds) emitted by the white pine. Note how both sesquiterpenes and terpenes were identified as volatile compounds from the coniferous tree
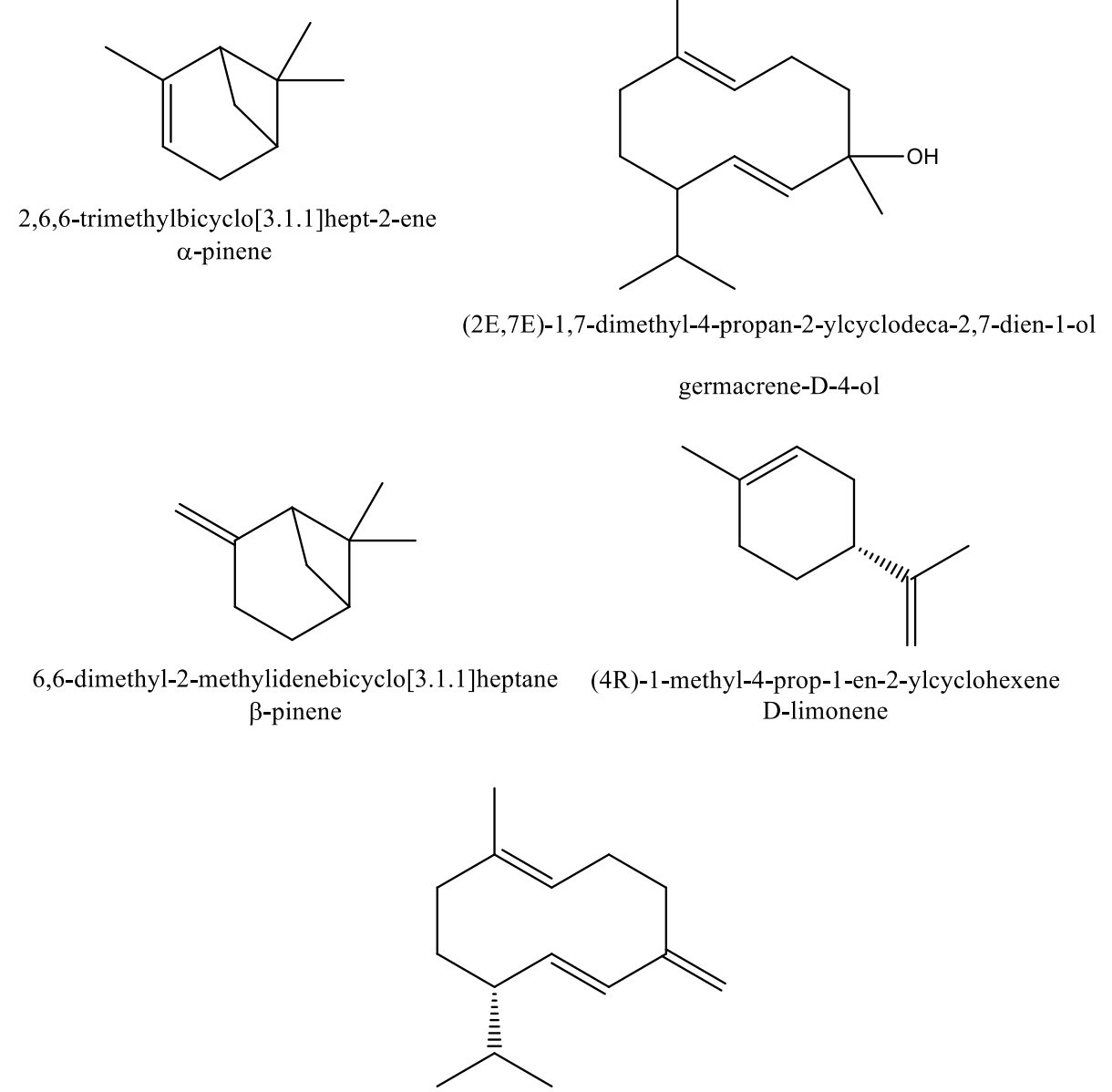

(1E,6E,8S)-1-methyl-5-methylidene-8-propan-2-ylcyclodeca-1,6-diene germacrene D

\section{Trees pack a double punch; the correlation between a higher forest coverage and reduced COVID-19 severity}

In a recent study some of us were able to glean more such insights into the importance of trees while considering the lesser impact COVID-19 seemed to have in the forested areas of Italy (Roviello and Roviello, 2021). Exposure to high levels of fine particulate matter (PM) in areas of Italy which had higher air pollution (likely exacerbated by their lack of trees) seemed to increase the mortality rate due to COVID-19. Conversely, by intercepting PM onto their leaves and other surfaces, trees mitigate air pollution while also emitting bioactive VOCs which strengthen the local populations immune system. This is likely the cause of the less severe impacts of COVID-19 in some mediterranean regions of Italy. Correlations have indeed been found between the level of air pollution present and the amount and severity of COVID-19 cases (Paital and Agrawal, 2021). The double protective role may be key to the lower COVID-19 induced mortality rate recorded in regions which have a higher density of trees (evergreens in particular). Forests play an essential shielding role against the spread of viral diseases by emitting immuno-modulating VOCs and by also offering dietary sources of antiviral compounds (Roviello and Roviello, 2021). Accessibility to outdoor spaces may also be of interest as people are able to safely escape the confines of their homes. Studies have indeed shown that people who spent more time in nature or who lived closer to wooded areas reported better mental wellbeing than those living in urban areas during the pandemic (Robinson et al. 2021). With people now spending much more time indoors due to the lockdowns, they are being subjected to higher amounts of indoor aerosols and ultrafine particles which have been shown in particular to be at the root of many respiratory disorders as well as increasing susceptibility to the COVID19 virus (Chen et al. 2021; He and Han, 2021). Spending more time outdoors, where there are less immediate sources of particulates and where trees act as air filters, is then of increased importance. Bringing this further, it is very likely that the proliferation of such respiratory diseases as COVID19 is directly related to the degradation of the worlds 
protective forest canopy, the loss of its protective aerosols and its air purifying and carbon sequestration capabilities [D Beresford-Kroeger 2021, personal communication, May].

\section{Discussion and perspectives}

The SARS-CoV-2-related pandemic has been the cause of some of the most dire challenges that mankind has had to face in the modern era. Few have been spared the virus devastating impacts which have spread from densely populated urban areas to the most vulnerable populations living deep in the world's last old growth forests. The recommended curfews and lockdown measures put in place to slow the spread of the coronavirus, especially for those living in cityscapes worldwide, has had unintended negative impacts on people's health. A much more sedentary lifestyle, an increase in unhealthy eating habits as well as mental health degradation have all combined to result in an impaired immune function and an enhanced risk of infection. To reverse these inadvertent consequences, moderate but sustained exercise is a feasible way of improving both physical as well as mental health in a time when anxiety and social isolation is on the rise. Thus, the regular practice of sports, even via online programming, is suggested as an accessible auxiliary tool which can help bolster the immune system against possible COVID-19 infection. Of course, a more specialized approach may be needed for those with certain pre-existing health conditions where a tailored physical training programme might be in order. Patients suffering from milder cases of COVID-19 could also benefit from an exercise program but should limit their physical activity to respiratory muscle training. Moderate physical exercise has many positive impacts on the body's immune system by counteracting immune deficiencies associated with the aging process and by significantly reducing the incidence of cardiovascular and respiratory diseases. Also worthy of note is the way it can alleviate the negative effects of home confinement whereby people are forced into a more sedentary lifestyle. In addition, exercise can help reduce the added risks associated with being overweight during this pandemic. Since obese, hypertensive and diabetic patients often experience the most severe forms of COVID-19, weight control, including moderate and adapted exercise, is beneficial for preventing viral respiratory infection and inflammation following SARSCoV-2 infection. Of course, further studies will be required to assess whether, for patients with cardiovascular and/or metabolic diseases, a physical training program would help build a stronger immune response against COVID-19 as well as to be able to associate a specific exercise regime to SARSCoV-2 patients.

Another important factor to keep in mind when looking at the benefits of a physical training program is its location.
Forest bathing, or the practice of spending time outside amongst particular trees, has scientifically proven benefits when it comes to human health and the strengthening of the immune system in particular. This is a widespread medical strategy in Japan, as well as certain other countries such as Norway and China, that has been used for many years. Patients there are prescribed walks in tree-rich areas (green prescriptions) as a preventative and curative measure for a variety of ailments. If we consider them from a molecular perspective, trees emit countless amounts of biogenic VOCs that offer an immunomodulatory effect lasting several weeks from when they are first inhaled. Crucially, forests also mitigate air pollution while forming important buffer zones which lower the risks of contact with wild animals and the pathogens they harbour, such as coronaviruses. In conclusion, sport performed in green spaces bolsters the body's ability to fight off COVID-19 and other infectious diseases through the combined benefits of physical exercise and the immunostimulatory effect provided by biogenic VOCs emitted by trees. With more and more evidence of the protective and purifying qualities of trees and forested areas, it is critical that efforts be made to protect current forests and increase green spaces if we are to succeed in ending the current pandemic and prevent more such devastating illnesses from making an appearance in the future.

Acknowledgements We are grateful to Diana Beresford-Kroeger (Canada) for useful discussion on the themes treated in this work. We would like to thank Dale Kristensen, Research Greenhouse Manager (Ret'd) at Queens University (Canada), for helping with the identification of the plant specimens in our photographs.

Authors Contributions Valentina Roviello, Melinda Gilhen-Baker, Caterina Vicidomini and Giovanni N. Roviello authors have contributed equally to this work.

Funding Not applicable.

Availability of Data and Material Not applicable.

\section{Declarations}

Conflict of interest The authors declare that they have no conflict of interest.

Ethics approval Not applicable.

Consent to participate Not applicable.

\section{References}

Alyammahi SK, Abdin SM, Alhamad DW, Elgendy SM, Altell AT, Omar HA (2021) The dynamic association between COVID19 and chronic disorders: An updated insight into prevalence, 
mechanisms and therapeutic modalities. Infect Genet Evol 87:104647. https://doi.org/10.1016/j.meegid.2020.104647

Ammar A, Brach M, Trabelsi K, Chtourou H, Boukhris O, Masmoudi L, Bouaziz B et al (2020) Effects of COVID-19 Home Confinement on Eating Behaviour and Physical Activity: Results of the ECLB-COVID19 International Online Survey. Nutrients 12(6) https://www.mdpi.com/2072-6643/12/6/1583\#cite

Beresford-Kroeger D (2013) Arboretum Borealis, A Lifeline of the Planet. The University of Michigan Press, Ann Arbor

Beresford-Kroeger D (2018) The Medicine of Trees. In The Ninth Haig Brown Memorial Lecture. Campbell River, British Columbia: Campbell River Community Arts Council

Beresford-Kroeger D (2019) "Bioplans for Forest Therapy.” In: Kotte D, Li Q, Shin WS, Michalsen A (eds) International Handbook of Forest Therapy, pp 48-59. Cambridge Scholars Publishing

Cervantes-Pérez E, Cervantes-Guevara G, Martínez-Soto Holguín CM, Cervantes-Pérez LA, Cervantes-Pérez G, Alonso Cervantes-Cardona G, González-Ojeda A, Fuentes-Orozco C, Ramirez-Ochoa $S$ (2020) Medical nutrition therapy in hospitalized patients with SARS-CoV-2 (COVID-19) infection in a non-critical care setting: knowledge in progress. Current Nutrition Report 9:309-315. https://doi.org/10.1007/s13668-020-00337-x

Chastin S, Abaraogu U, Bourgois JG, Dall PM, Darnborough J, Duncan E, Dumortier J et al (2021) Effects of regular physical activity on the immune system, vaccination and risk of community-acquired infectious disease in the general population: systematic review and meta-analysis. Sports Med 51:1673-1686. https://doi.org/10. 1007/s40279-021-01466-1

Chathappady House NN, Palissery S, Sebastian H (2021) Corona viruses: a review on SARS, MERS and COVID-19. Microbiol Insights 14:117863612110024. https://doi.org/10.1177/11786 361211002481

Chen B, Jia P, Han J (2021) Role of indoor aerosols for COVID-19 viral transmission: a review. Environ Chem Lett 19:1953-1970. https:// doi.org/10.1007/s10311-020-01174-8

Clarke F, Kotera Y, McEwan K (2021) A qualitative study comparing mindfulness and shinrin-yoku (forest bathing): practitioners' perspectives. Sustainability 13(12):6761. https://doi.org/10.3390/ su13126761

Codella R, Chirico A, Lucidi F, Ferrulli A, La Torre A, Luzi L (2021) The immune-modulatory effects of exercise should be favorably harnessed agains COVID-19. J Endocrinol Invest 44:1119-1122. https://doi.org/10.1007/s40618-020-01403-5

Costanzo M, De Giglio MA, Roviello GN (2020) SARS-CoV-2: recent reports on antiviral therapies based on lopinavir/ritonavir, darunavir/umifenovir, hydroxychloroquine, remdesivir, favipiravir and other drugs for the treatment of the new coronavirus. Curr Med Chem 27(27):4536-4541

Costanzo M, De Giglio MAR, Roviello GN (2021) Anti-Coronavirus Vaccines: Past Investigations on SARS-CoV-1 and MERS-CoV, the Approved Vaccines from BioNTech/Pfizer, Moderna, Oxford/ AstraZeneca and others under Development Against SARS-CoV-2 Infection. Curr Med Chem. https://doi.org/10.2174/0929867328 666210521164809

da Silveira MP, da Silva Fagundes KK, Bizuti MR, Starck É, Rossi RC, de Resende e Silva DT (2020a) Physical exercise as a tool to help the immune system against COVID-19: an integrative review of the current literature. Clin Exp Med 21(1):15-28. https://doi.org/ 10.1007/s10238-020-00650-3

Dai H, Han J, Lichtfouse E (2021) Smarter cures to combat COVID-19 and future pathogens: a review. Environ Chem Lett 19:2759-2771. https://doi.org/10.1007/s10311-021-01224-9

Dalamaga M, Christodoulatos GS, Karampela I, Vaillianou N, Apovian CM (2021) Understanding the co-epidemic of obesity and COVID-19: current evidence, comparison with previous epidemics, mechanisms, and preventive and therapeutic perspectives. Curr Obes Rep. https://doi.org/10. 1007/s13679-021-00436-y

Despommiers D, Ellis BR, Wilcox BA (2006) The role of ecotones in emerging infectious diseases. EcoHealth 3:281-289. https://doi. org/10.1007/s10393-006-0063-3

Doimo I, Masiero M, Gatto P (2020) Forest and wellbeing: bridging medical and forest research for effective forest-based initiatives. Forests 11(8):791. https://doi.org/10.3390/f11080791

Dominski FH, Brandt R (2020) Do the benefits of exercise in indoor and outdoor environments during the covid-19 pandemic outweigh the risks of infection? Sport Sciences for Health 16:583588. https://doi.org/10.1007/s11332-020-00673-z

He S, Han J (2021) Electrostatic fine particles emitted from laser printers as potential vectors for airborne transmission of COVID19. Environ Chem Lett 19:17-24. https://doi.org/10.1007/ s10311-020-01069-8

Iddir M, Brito A, Dingeo G, Fernandez Del Campo SS, Samouda H, La Frano MR, Bohn T (2020) Strengthening the immune system and reducing inflammation and oxidative stress through diet and nutrition: considerations during the COVID-19 crisis. Nutrients 12(6):1562. https://doi.org/10.3390/nu12061562

Isidorov VA, Zenkevich IG, Loffe BV (1985) Volatile organic compounds in the atmosphere of forests. Atmos Environ 19(1):1-8

Jesus I, Vanhee V, Deramaudt TB, Bonay M (2021) Promising effects of exercise on the cardiovascular, metabolic and immune system during COVID-19 period. J Hum Hypertens 35(1):1-3

Jones R, Tarter R, Miner Ross A (2021) Greenspace interventions, stress and cortisol: a scoping review. Int J Environ Res Public Health 18(6):2802. https://doi.org/10.3390/ijerph18062802

Juergens U (2014) Anti-Inflammatory Properties of the Monoterpene 1.8-Cineole: Current Evidence for Co-Medication in Inflammatory Airway Diseases. Drug Research 64(12):638-46. https://doi. org/10.1055/s-0034-1372609.

Khoramipour K, Basereh A, Hekmatikar AA, Castell L, Ruhee RT, Suzuki K (2021) Physical activity and nutrition guidelines to help with the fight against COVID-19. J Sports Sci 39(1):101-107

Kim T, Song B, Cho K S, and Lee I-S (2020) Therapeutic Potential of Volatile Terpenes and Terpenoids from Forests for Inflammatory Diseases. International Journal of Molecular Sciences 21(6). https://www.mdpi.com/1422-0067/21/6/2187/htm.

Lakicevic N, Moro T, Paoli A, Roklicer R, Trivic T, Cassa S, Drid P (2020) Stay fit, don't quit: geriatric exercise prescription in COVIF-19 pandemic. Aging Clin Exp Res 32:1209-1210. https:// doi.org/10.1007/s40520-020-01588-y

Lange KW, and Nakamura Y (2020) Movement and Nutrition in COVID-19. Movement and Nutrition in Health and Disease, 4

Li Quing (2019) The Potential Preventative Effect of Forest Therapy on Lifestyle-Related Diseases. In International Handbook of Forest Therapy, edited by Dieter Kotte, Quing Li, Won Sop Shin, and Andreas Michalsen, 124-38. Cambridge Scholars Publishing

Malaguarnera L, Cristaldi E, Vinci M, Malaguarnera M (2008) The role of exercise on the innate immunity of the elderly. Eur Rev Aging Phys Activ 5:43-49. https://doi.org/10.1007/s11556-007-0028-8

Montgomery JM, Wong C-M, Lai H-K, Ou C-Q, Ho S-Y, Chan K-P, Thach T-Q, Yang L, Chau Y-K, Lam T-H, Hedley AJ, Peiris JSM (2008) Is exercise protective against influenza-associated mortality? PLoS ONE 3(5):e2108. https://doi.org/10.1371/journal.pone. 0002108

Nam S-Y, Chung CK, Seo J-H, Rah S-Y, Kim H-M, Jeong H-J (2014) The therapeutic efficacy of $\alpha$-pinene in an experimental mouse model of allergic rhinitis. Int Immunopharmacol 23(1):273-282. https://doi.org/10.1016/j.intimp.2014.09.010

Ochiai H (2019) The Psychological and Psychosomatic Benefits of Forest Therapy. In International Handbook of Forest Therapy, edited by Dieter Kotte, Quing Li, Won Sop Shin, and Andreas Michalsen, 91-105. Cambridge Scholars Publishing. 
Ouellet C, Harbilas D, Garofalo C, Levy E, and Haddad P S (2016) Balsam Poplar (Populus Balsamifera), a Traditional Eastern James Bay Cree Medicine, Exerts a Limited Modulation of Intestinal Lipid Homeostasis in an Animal Model of Diet-Induced Obesity." Journal of Diabetes Research and Therapy 2(3)

Paital B, Agrawal PK (2021) Air pollution by NO2 and PM2.5 Explains COVID-19 infection severity by overexpression of aniotensin converting enzyme 2 in respiratory cells: a review. Environ Chem Lett 19:25-42. https://doi.org/10.1007/s10311-020-01091-w

Peterfalvi A, Meggyes M, Makszin L, Farkas N, Miko E, Miseta A, and Szereday L (2021) Forest Bathing Always Makes Sense: Blood Pressure-Lowering and Immune System-Balancing Effects in Late Spring and Winter in Central Europe. International Journal of Environmental Research and Public Health 18(4). https://doi.org/ 10.3390/ijerph18042067.

Robinson JM, Brindley P, Cameron R, MacCarthy D, Jorgensen A (2021) Nature's role in supporting health during the COVID-19 pandemic: a geospatial and socioecological study. Int J Environ Res Public Health 18(5):2227. https://doi.org/10.3390/ijerph1805 2227

Roviello V, Roviello GN (2021) Lower COVID-19 mortality in italian forested areas suggests immunoprotection by mediterreanean plants. Environ Chem Lett 19(1):699-710

Salgado-Aranda R, Pérez-Castellano N, Núñez-Gil I, Josué Orozco A, Torres-Esquivel N, Flores-Soler J, Chamaisse-Akari A et al (2021) Influence of baseline physical activity as a modifying factor on COVID-19 mortality: a single-center, retrospective study. Infectious Diseases Therapy 10:801-814. https://doi.org/10.1007/ s40121-021-00418-6

Salvadori A, Fanari P, Marzullo P, Codecasa F, Tovaglieri I, Cornacchia M, Terruzzi I et al (2021) Playing around the Anaerobic threshold during COVID-19 pandemic: advantages and disadvantages of adding bouts of anaerobic work to aerobic activity in physical treatment of individuals with obesity. Acta Diabetol. https://doi.org/10.1007/s00592-021-01747-1

Seifert G, Jeitler M, Stange R, Michalsen A, Cramer H, Brinkhaus B, Esch $\mathrm{T}$ et al (2020) The relevance of complementary and integrative medicine in the COVID-19 pandemic: a qualitative review of the literature. Front Med. https://doi.org/10.3389/fmed.2020. 587749

Sen M (2020) Forests: at the heart of a green recovery from the COVID-19 pandemic

Sepúlveda-Loyola W, Rodríguez-Sánchez I, Pérez-Rodríguez P, Ganz F, Torralba R, Oliveira DV, Rodríguez-Mañas L (2020) Impact of social isolation due to COVID-19 on health in older people: mental and physical effects and recommendations. J Nutr Health Aging 24:938-947. https://doi.org/10.1007/s12603-020-1500-7

Shek PN, Shephard RJ (1998) Physical exercise as a human model of limited inflammatory response. Can J Physiol Pharmacol 76(5):589-597. https://doi.org/10.1139/y98-040

da Silveira M P, Da Silva Fagundes K K, Bizuti M R, Starck E, Rossi R C, and e Silva D T D R (2020) Physical Exercise as a Tool to Help the Immune System against COVID-19: An Integrative Review of the Current Literature. Clinical and Experimental Medicine, 1-14

Thompson ID, Simard JH, Titman RD (2006) Historical Changes in White Pine (Pinus Strobus L.) Density in Algonquin Park, Ontario, during the 19th Century. Natural Areas J 26(1):61-71

Timko Olsen E R, Hansen M M, and Vermeesch A (2020) Mindfulness and Shinrin-Yoku: Potential for Physiological and Psychological
Interventions during Uncertain Times. International Journal of Environmental Research and Public Health 17(24). https://www. mdpi.com/1660-4601/17/24/9340/htm.

Toma S, Bertman S (2011) The atmospheric potential of biogenic volatile organic compounds from needles of white pine (Pinus Strobus) in Northern Michigan. Atmosp Chem Phys Discuss 11(9):26849-26865. https://doi.org/10.5194/acpd-11-26849-2011

Toma S, Bertman S (2009) The Study of Biogenic Volatile Organic Compounds from Needles of White Pine (Pinus Strobus) in Northern Michigan. AGU Fall Meeting Abstracts December: B11C-0490

Uprety Y, Asselin H, Bergeron Y (2013) Cultural importance of white pine (Pinus Strobus L.) to the kitcisakik algonquin community of western Quebec Canada. Can J Forest Res 43(6):544-551

Wang S-Y (2019) The Effects of Phytoncides. In International Handbook of Forest Therapy, edited by Kotte. Dieter, Quing Li, Won Sop Shin, and Andreas Michalsen, 140-47. Cambridge Scholars Publishing

Wen Y, Yan Q, Pan Y, Gu X, Liu Y (2019) Medical Empirical Research on forest bathing (Shinrin-Yoku): a systematic review. Environ Health Prev Med. https://doi.org/10.1186/s12199-019-0822-8

Worth H, Dethlefsen U (2012) Patients with asthma benefit from concomitant therapy with cineole: a placebo-controlled, DoubleBlind Trial. J Asthma 49(8):849-853. https://doi.org/10.3109/ 02770903.2012 .717657

Xu S, Baker JS, Ren F (2021) The positive role of tai chi in responding to the COVID-19 pandemic. Int J Environ Res Public Health 18(14):7479. https://doi.org/10.3390/ijerph18147479

Yau KK-Y, Loke AY (2020) Effects of forest bathing on pre-hypertensive and hypertensive adults: a review of the literature. Environ Health Prev Med. https://doi.org/10.1186/s12199-020-00856-7

Yu C-P, and Lee H-Y (2019) Benefits of Forest Therapy as a Public Health Approach. In International Handbook of Forest Therapy, edited by Dieter Kotte, Quig Li, Won Sop Shin, and Andreas Michalsen, 478-92. Cambridge Scholars Publishing

Zhang X, Chen B, Jia P (2021) Locked on Salt? Excessive Consumption of High Sodium Foods during COVID-19 presents an underappreciated public health risk: a review. Environ Chem Lett. https://doi.org/10.1007/s10311-021-01257-0

Zhou D, Dejnirattisai W, Supasa P, Liu C, Mentzer AJ, Ginn HM, Zhao Y, Duyvesteyn HME, Tuekprakhon A, Nutalai R, Wang B, Paesen GC, Lopez-Camacho C, Slon-Campos J, Hallis B, Coombes N, Bewley K, Charlton S, Walter TS, Skelly D, Lumley SF, Dold C, Levin R, Dong T, Pollard AJ, Knight JC, Crook D, Lambe T, Clutterbuck E, Bibi S, Flaxman A, Bittaye M, BelijRammerstorfer S, Gilbert S, James W, Carroll MW, Klenerman P, Barnes E, Dunachie SJ, Fry EE, Mongkolsapaya J, Ren J, Stuart DI, Screaton GR (2021) Evidence of escape of SARS-CoV-2 variant B.1.351 from natural and vaccine-induced sera. Cell 184 (9):2348-2361.e2346. https://doi.org/10.1016/j.cell.2021.02.037

Publisher's Note Springer Nature remains neutral with regard to jurisdictional claims in published maps and institutional affiliations. 